\title{
DEPENDENCE OF MARTENSITE START TEMPERATURE ON FINE AUSTENITE GRAIN SIZE
}

\author{
A. García-Junceda, C. Capdevila, F.G. Caballero, C. García de Andrés \\ Materalia Research Group, Department of Physical Metallurgy, Centro Nacional de \\ Investigaciones Metalúrgicas (CENIM), Consejo Superior de Investigaciones \\ Científicas (CSIC), Avda. Gregorio del Amo, 8, 28040 Madrid, Spain, \\ www.cenim.csic.es
}

\begin{abstract}
It has been broadly reported that determination of the martensite start temperature in steels, $\mathrm{M}_{\mathrm{s}}$, requires a complete description of their chemical composition. Recently, several neural networks models considering both chemical composition and austenite grain size (AGS) have been developed. Such models predict a moderate dependence of $\mathrm{M}_{\mathrm{s}}$ with AGS. The present work examines the validity of existing neural network models, but focusing on fine AGS (below $5 \mu \mathrm{m}$ ).
\end{abstract}

Keywords: Martensite start temperature; Austenite grain size.

The temperature at which austenite transforms to martensite during cooling of steels, hereafter named as $M_{s}$, and the factors that affects its value have been broadly investigated. It is well known that $\mathrm{M}_{\mathrm{s}}$ is strongly dependent on the austenite chemical composition. Since decades it has been clarified the effect on $\mathrm{M}_{\mathrm{s}}$ of different alloying elements in solid solution, the additive effect of individual elements, and the negligible effect of impurities and small amounts of elements [1-6]. Thus, different empirical equations have been reported. All these investigations pointed out that carbon is the alloying element with the strongest influence on decreasing of the $\mathrm{M}_{\mathrm{s}}$ values. However, the effect of austenite grain size (AGS) has not been generally included in such equations.

On the other hand, artificial neural network models have been developed during the last years to predict the $\mathrm{M}_{\mathrm{s}}$ from chemical composition [7], and both chemical composition and AGS [8]. The AGS values considered in those models range from 5 to $340 \mu \mathrm{m}$ in average diameter. The predicted results showed a monotonous and smooth decrease of Ms with AGS, even for AGS values smaller than $5 \mu \mathrm{m}$. It is the aim of this paper to analyze the behavior of Ms with small AGS values in a commercial dual phase steel.

The steel used in this investigation was vacuum melted, cast into $60 \mathrm{~kg}$ ingot and hot rolled. Semi rolled slabs, $30 \mathrm{~mm}$ thick, were soaked at $1200{ }^{\circ} \mathrm{C}$ for $45 \mathrm{~min}$. and hot rolled to about $3 \mathrm{~mm}$ in several passes, finishing at $900^{\circ} \mathrm{C}$. Two different cooling rates, $\mathrm{CR},\left(7\right.$ and $\left.60{ }^{\circ} \mathrm{C} / \mathrm{s}\right)$ and two different coiling temperatures, CT, $\left(500\right.$ and $\left.650{ }^{\circ} \mathrm{C}\right)$, were tested in the pilot hot-rolling mill (Table 1). Hot rolled samples were then cold rolled to sheets $0.9 \mathrm{~mm}$ thick. The steel composition, in wt. pct., is Fe-0.15C-1.9Mn-0.2Si-02Cr$0.03 \mathrm{Al}$.

Because of the different combinations of CR and CT during hot rolling schedule, four different as-cold rolled microstructures with different amounts of ferrite, pearlite, and bainite/martensite were obtained. A set of cold rolled $12 \mathrm{~mm}$ x $2 \mathrm{~mm} \times 0.9 \mathrm{~mm}$ samples were machined parallel to the rolling direction and austenitized at a rate of $5{ }^{\circ} \mathrm{C} / \mathrm{s}$ to different temperatures and times. Some of the austenitization cycles were performed at 
temperatures very close to $\mathrm{Ac}_{3}\left(\approx 850{ }^{\circ} \mathrm{C}\right.$ for treated samples) in order to reach very fine AGS. Austenite transforms to martensite during subsequent quenching. For this purpose, the heating and cooling devices of a high-resolution dilatometer were used [9]. The experimental values of $\mathrm{M}_{\mathrm{s}}$ were determined from the dilatometric curves registered during quenching. Previous austenite grain boundaries were revealed in those samples by means of a saturated aqueous picric acid plus a wetting agent [10], then using an image analyzer on acquired optical micrographs, austenite grain size was measured as the mean value as the equivalent circle diameter. Figure 1 shows some examples of those micrographs.

Table 2 summarizes the austenitizing treatments, the AGS measured and the experimental $\mathrm{M}_{\mathrm{s}}$ values obtained for samples austenitized at temperature close to $\mathrm{Ac}_{3}$ temperature, where the AGS varies between 2.6 and $4.7 \mu \mathrm{m}$. Results suggest that the $\mathrm{M}_{\mathrm{s}}$ is very sensitive to small variations in AGS, i.e. small increases in AGS raise $M_{s}$ significantly. On the other hand Table 3 reveals that influence of coarse AGS on Ms is almost negligible. Figure 2 showing the evolution of Ms with fine and coarse AGS, clearly reveals that a slight increase in AGS, below $5 \mu \mathrm{m}$, produces a substantial increase in Ms, meanwhile coarser AGS values have an almost negligible influence on $\mathrm{M}_{\mathrm{s}}$. It is the goal of this paper to explain such behavior.

As it was very well documented by Nishiyama [11], the initiation temperature and progress of martensitic transformation, are controlled by the chemical and non-chemical free energies of the system. The chemical free energy difference is the transformation driving force and is converted to non-chemical free energy. The latter partly goes into the energy of lattice imperfections inevitable upon transformation.

Several studies [11-15] have reported that in ferrous systems the AGS effect on $M_{s}$ is likely caused by the reduction of the energy needed for the complementary shear during transformation, which originates in the elimination of lattice imperfections due to higher austenitization temperature [11]. Likewise, the nucleation of martensite may be boosted by an increase of frozen-in vacancies into the austenite grain due to higher quenching temperatures, which means that the increase in vacancies makes austenite less stable by increasing martensite nucleation sites [11]. Therefore, $M_{s}$ should increase as austenitization temperature increases.

Alternatively, Machlin and Cohen [12] concluded from studies of Fe-29Ni that martensite transformation is independent of austenitizing temperature; grain size being constant. Thus, the variation in $\mathrm{M}_{\mathrm{s}}$ is due to grain size variability. This is consistent with the results presented by Kitahara et al. [16], which showed that the $M_{s}$ decreases as austenite grain size is reduced. For that purpose, the authors produced a sub-micron austenitic microstructure increasing the number of the accumulative roll bonding (ARB) cycles in a Fe-28Ni alloy. The tendency to decrease $\mathrm{M}_{\mathrm{s}}$ as AGS does is in line with our results. However, it should be noted that the reported ultra-fine grain structures were produced by severe plastic deformation, a process involving many dislocations and lowangle boundaries, whereas we are dealing with recrystallized grain structures. It is reasonable to assume that austenite strength increases during the ARB process by both grain-refinement strengthening and strain-hardening. Because martensite transformation accompanies with shear strain, at the beginning of the transformation, certain degree of shear should be accommodated by deformation of austenite. Strengthening of austenite makes the accommodation difficult, which would be the reason why the $M_{s}$ monotonously decreased with increasing the ARB strain, i.e. smaller grain sizes.

The reported behavior of decreasing $\mathrm{M}_{\mathrm{s}}$ with decreasing AGS it has been also observed in nanomaterials. Many researches [17-18] reveal that martensite transformation in some materials, such as $\mathrm{Fe}, \mathrm{Co}, \mathrm{Fe}-\mathrm{Ni}$ alloy and $\mathrm{ZrO}$, will be suppressed if their grain 
size is smaller that a critical value. For example, in Co the $\beta$ (fcc) $\rightarrow \alpha$ (hcp) martensite transformation will be suppressed, being $\beta$ (fcc) stable at room temperature, when its grain size is less than $35 \mathrm{~nm}$, as predicted by theory [17].

However, we would like to empathize that the behavior of decreasing Ms with AGS described in this work corresponds to the micro and no nano austenite grains. It has been established experimentally that martensite transformation in micrometer or larger crystals requires the presence of dislocations in addition to supercooling beyond the thermodynamical equilibrium temperature $T_{0}$. But dislocations can not exist in nanocrystals, and the martensite transformation takes place with features quite different from those in micrometer crystals [19].

Brofman and Ansell [14] proposed that the Hall-Petch strengthening of the austenite explains the depression of $\mathrm{M}_{\mathrm{s}}$ as AGS decreases. Hirth [20] has reviewed various grain size strengthening theories in metals and reported some experimental evidence for the relation, $\rho \propto 1 / \mathrm{D}$, where $\rho$ is the dislocation density and $\mathrm{D}$ is the austenite grain diameter. Thus, an increase in dislocation density related to a decrease in AGS will result in a strengthening of the austenitic matrix by the Hall-Petch effect, increasing the resistance of the austenite to plastic deformation locally as well as macroscopically, which means a bigger impediment to martensite transformation by increasing the nonchemical free energy opposing the transformation.

Additionally, Cech and Turnbull [21] have demonstrated that martensitic transformation in Fe-30Ni alloy crystals with grain sizes between 25 and $100 \mu \mathrm{m}$ is suppressed as the diameter of the crystals decreases. Using those results Cohen and Olson [22] demonstrated that can be fitted, with a good level of agreement, by a probability expression given by $\mathrm{p}=1-\exp (-\lambda \mathrm{v})$, where $\mathrm{p}$ represents the fraction of the crystals containing martensite, $\mathrm{v}$ the grain volume, and $\lambda$ the probability for nucleation of martensite per unit volume which depends on the temperature. This equation states that the probability of the nucleation event to take place decreases exponentially as the grain sizes decreases.

All these former works explain the drop of $\mathrm{M}_{\mathrm{s}}$ with decreasing AGS. However, the change of slope in $\mathrm{M}_{\mathrm{s}}$ vs AGS plot for AGS $>5 \mu \mathrm{m}$ presented in Fig. 2 remains unexplained. In this sense, Umemoto an Owen [23] experimentally demonstrated a clear dependence of $\mathrm{M}_{\mathrm{s}}$ with grain size in Fe-31Ni-0.28C steel. They studied the influence of AGS ranging from $8 \mu \mathrm{m}$ to $450 \mu \mathrm{m}$ on Ms, finding that Ms increases rapidly with increase in grain size from the smallest values up to about $150 \mu \mathrm{m}$, where a plateau is reached. For specimens with AGS $\geq 150 \mu \mathrm{m} \mathrm{M}_{\mathrm{s}}$ does not change significantly with increasing AGS. It was argued by the authors that the change from a steep to a more gradual slope in the $M_{s}$ vs AGS plot coincide with a transition in the morphology of martensite. It was reported that thin-plate martensite is formed for the finest AGS, meanwhile lenticular martensite is formed for coarser ones.

In our work, a similar behavior is found but with considerably smaller values of transition AGS $(<5 \mu \mathrm{m})$, and we speculate that change in the martensite morphology might also be responsible for the reported behavior of $\mathrm{M}_{\mathrm{s}}$ vs. AGS. However, in this work it has not been possible to extract a comprehensive understanding of the existence of a critical point of $5 \mu \mathrm{m}$ AGS in the change of $\mathrm{M}_{\mathrm{s}}$ with AGS, because the experimental characterization available has been shown to be insufficient for analysis purpose. In future experimental work, it would be useful to perform TEM examination to clarify this point.

Finally, results presented in Fig. 2 could also be interpreted as a validation of the neural network model tested [7-8]. Meanwhile predicted $\mathrm{M}_{\mathrm{s}}$ values fit considerably well to 
those experimentally determined for AGS bigger than $5 \mu \mathrm{m}$, the predictions for AGS < $5 \mu \mathrm{m}$ does not follow the experimentally detected tendency of $\mathrm{M}_{\mathrm{s}}$. The reason for such behavior remains in the data base used to build the models. Since this neural network was developed considering steels with AGS values always bigger than $5 \mu \mathrm{m}$, it seems that it does not detect appreciable variations in the range of the very fine AGS studied in this investigation.

Summarizing, it can be concluded that in the commercial dual phase steel studied there is a strong dependence of the $\mathrm{M}_{\mathrm{s}}$ on very fine austenite grain size. It has been observed in annealed and quenched samples with a fully martensitic microstructure that a slight increase in the very fine AGS resulted in higher $\mathrm{M}_{\mathrm{s}}$ values.

\section{Acknowledgements}

The authors acknowledge financial support from the European Union through the European Coal and Steel Community programme (ECSC-7210-PR-349) and from the Spanish Ministerio de Educación y Ciencia (Special Action MAT 2002-10808-E).

\section{References}

[1] P. Payson, C.H. Savage, Trans. Am. Soc. Met. 33 (1944) 261.

[2] L.A.Carapella, Metal. Prog. 46 (1944) 108.

[3] E.S .Rowland, S.R.Lyle, American Society for Metals 37 (1946) 27.

[4] R.A. Grange, H.M. Stewart, Trans. AIME. 167 (1946) 467.

[5] K.W. Andrews, J. Iron Steel Inst. 203 (1965) 727.

[6] C.Y. Kung, J.J. Rayment, Metall. Trans. A 13 (1982) 328.

[7] C. Capdevila, F.G. Caballero, C. García de Andrés, ISIJ Int. 42 (2002) 894.

[8] C. Capdevila, F.G. Caballero, C. García de Andrés, Mater. Sci. Technol. 19 (2003) 581.

[9] C. García de Andrés, F.G. Caballero, C. Capdevila, L.F. Alvarez, Mater. Charact. 48 (2002) 101.

[10] C. García de Andrés, M.J. Bartolomé, C. Capdevila, D. San Martín, F.G. Caballero, V. López, Mater. Charact. 46 (2001) 389.

[11] Z. Nishiyama, Martensitic Transformation, in: M. Fine, M. Meshi, C. Wayman (eds.), Academic Press, New York, 1978.

[12] E.M. Breinan, G.S. Ansell, Metall. Trans. 1 (1970) 1513.

[13] O.A. Ankara, A.S. Sastri, D.R.F. West, J. Iron and Steel Institute May (1966) 509.

[14] P.J. Brofman, G.S. Ansell, Metall. Trans. A 14A (1983) 1929.

[15] T. Maki, S. Shimooka, I. Tamura, Metall. Trans. 2 (1971) 2944.

[16] H Kitahara, N Tsuji, Y Minamino, Mat. Sci. Eng. A 438-440 (2006) 233-236

[17] Y. Rong, Current Opinion in Solid State and Materials Science 9 (2005) 287-295.

[18] Q. Meng, N. Zhou, Y. Rong, S. Chen, T. Y. Hsu, X. Zuyao, Acta Materialia 50 (2002) 4563-4570.

[19] T. Suzuki, M. Shimono, M. Wuttig. Scr. Mater. 44 (2001) 1979.

[20] J.P. Hirth: Metall. Trans. 3 (1972) 3047.

[21] R. E. Cech and D. Turnbull, Trans. AIME. 206, 124 (1956).

[22] M. Cohen and G. B. Olson, in Proceedings of the First JIM International Symposium on New Aspect of Martensitic Transformation, p. 93, Japan Institute of Metals, Sendai (1976).

[23] M. Umemoto, W.S. Owen, Metall. Trans. 5 (1975) 2041. 


\section{Table and Figure Captions}

Table 1. Hot rolled conditions of tested samples.

Table 2. $\mathrm{M}_{s}$ evolution with fine AGS.

Table 3. $\mathrm{M}_{s}$ evolution with coarse AGS.

Figure 1. Optical micrographs of: a) Sample $\mathrm{S} 1, \mathrm{AGS}=(3.0 \pm 1.1) \mu \mathrm{m}$, b) Sample S3, $\mathrm{AGS}=(4.7 \pm 1.8) \mu \mathrm{m}$. Etching with saturated aqueous picric acid [10].

Figure 2. Comparison of experimental $\mathrm{M}_{\mathrm{s}}$ obtained from different fine and coarse AGS with $\mathrm{M}_{\mathrm{s}}$ calculated from neural network (NN) model [8]. 


\section{Tables}

Table 1. Hot rolled conditions of tested samples.

\begin{tabular}{ccc}
\hline Sample & $\mathrm{CR},{ }^{\circ} \mathrm{C} / \mathrm{s}$ & $\mathrm{CT},{ }^{\circ} \mathrm{C}$ \\
\hline $\mathrm{S} 1$ & 7 & 500 \\
\hline $\mathrm{S} 2$ & 60 & 500 \\
\hline $\mathrm{S} 3$ & 7 & 650 \\
\hline $\mathrm{S} 4$ & 60 & 650
\end{tabular}

CR Cooling rate; CT Coiling temperature

Table 2. $\mathrm{M}_{s}$ evolution with fine AGS.

\begin{tabular}{ccccc}
\hline Sample Soaking Temperature & $\begin{array}{c}\text { Soaking Time } \\
\left({ }^{\circ} \mathrm{C}\right)\end{array}$ & $\begin{array}{c}\mathrm{M}_{\mathrm{s}} \\
(\mathrm{s})\end{array}$ & $\begin{array}{c}\text { AGS } \\
(\mu \mathrm{m})\end{array}$ \\
\hline S1 & 850 & 1 & $361 \pm 10$ & $3.0 \pm 1.1$ \\
& 850 & 20 & $364 \pm 9$ & $3.6 \pm 1.3$ \\
& 850 & 100 & $369 \pm 10$ & $3.8 \pm 1.5$ \\
\hline S2 & 850 & 1 & $362 \pm 10$ & $2.6 \pm 1.2$ \\
& 850 & 20 & $366 \pm 11$ & $3.3 \pm 1.3$ \\
& 850 & 100 & $368 \pm 10$ & $3.2 \pm 1.3$ \\
\hline S3 & 850 & 20 & $374 \pm 8$ & $4.2 \pm 1.7$ \\
& 850 & 100 & $375 \pm 10$ & $4.7 \pm 1.8$ \\
\hline S4 & 850 & 20 & $370 \pm 9$ & $3.6 \pm 1.4$ \\
& 850 & 100 & $378 \pm 10$ & $4.7 \pm 1.6$ \\
\hline
\end{tabular}

Table 3. $\mathrm{M}_{s}$ evolution with coarse AGS.

\begin{tabular}{ccccc}
\hline Sample Soaking Temperature & $\begin{array}{c}\text { Soaking Time } \\
(\mathrm{s})\end{array}$ & $\begin{array}{c}\mathrm{M}_{\mathrm{s}} \\
\left({ }^{\circ} \mathrm{C}\right)\end{array}$ & $\begin{array}{c}\text { AGS } \\
(\mu \mathrm{m})\end{array}$ \\
\hline S1 & 950 & 20 & $380 \pm 9$ & $4 \pm 1$ \\
& 1050 & 20 & $379 \pm 10$ & $7 \pm 1$ \\
& 1150 & 20 & $385 \pm 11$ & $21 \pm 3$ \\
& 1200 & 20 & $390 \pm 8$ & $29 \pm 4$ \\
\hline S2 & 950 & 20 & $372 \pm 8$ & $4 \pm 1$ \\
& 1050 & 20 & $375 \pm 11$ & $6 \pm 1$ \\
& 1150 & 20 & $385 \pm 12$ & $18 \pm 2$ \\
& 1200 & 20 & $392 \pm 9$ & $25 \pm 3$ \\
\hline S3 & 950 & 20 & $382 \pm 9$ & $5 \pm 1$ \\
& 1050 & 20 & $390 \pm 10$ & $7 \pm 1$ \\
& 1150 & 20 & $373 \pm 11$ & $18 \pm 3$ \\
& 1200 & 20 & $388 \pm 10$ & $26 \pm 3$ \\
\hline S4 & 950 & 20 & $384 \pm 9$ & $6 \pm 1$ \\
& 1050 & 20 & $386 \pm 8$ & $10 \pm 1$ \\
& 1150 & 20 & $390 \pm 11$ & $26 \pm 3$ \\
& 1200 & 20 & $393 \pm 10$ & $24 \pm 3$ \\
\hline
\end{tabular}




\section{Figures}

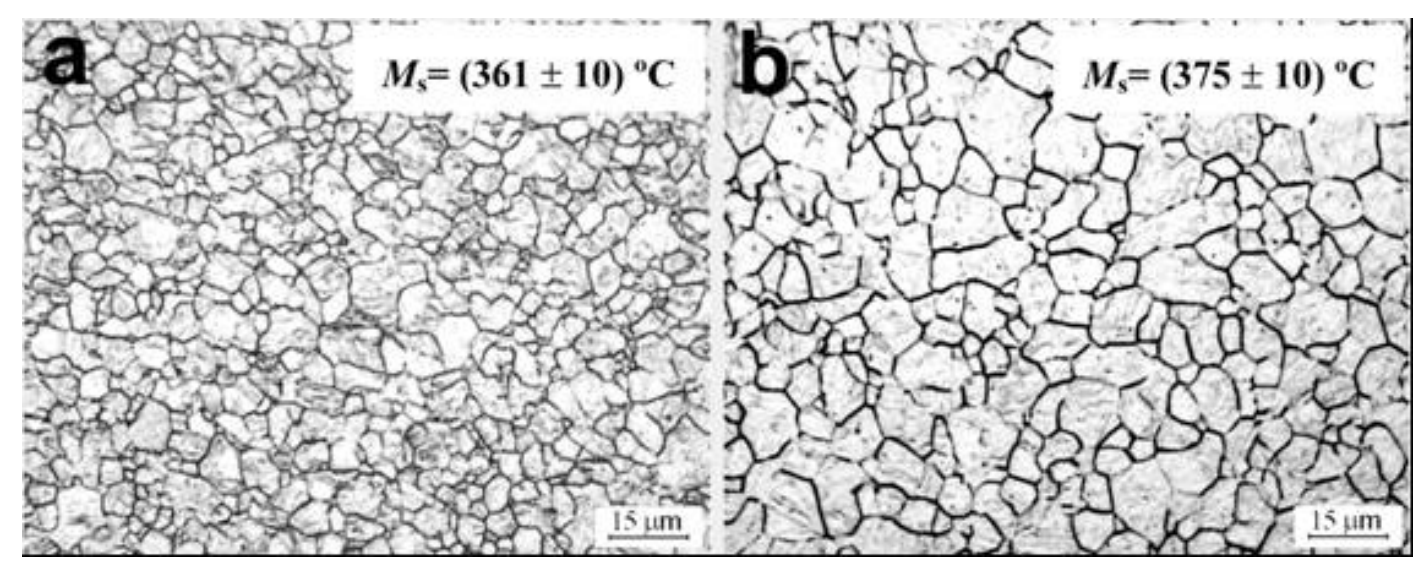

Figure 1. Optical micrographs of: a) Sample $\mathrm{S} 1, \mathrm{AGS}=(3.0 \pm 1.1) \mu \mathrm{m}$, b) Sample $\mathrm{S} 3$, $\mathrm{AGS}=(4.7 \pm 1.8) \mu \mathrm{m}$. Etching with saturated aqueous picric acid [10].

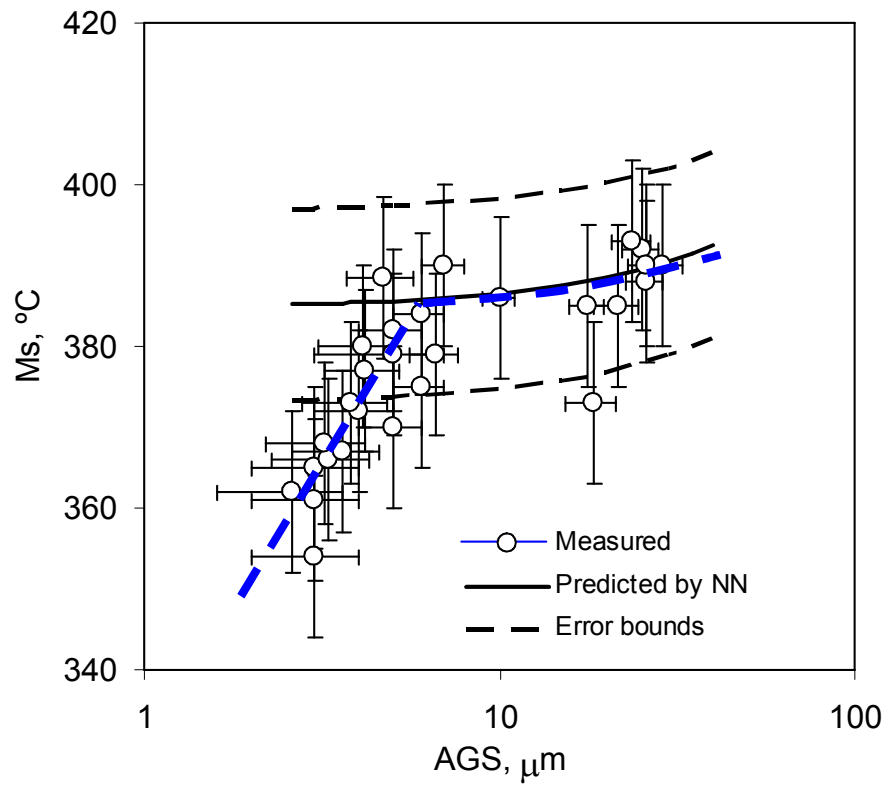

Figure 2. Comparison of experimental $\mathrm{M}_{\mathrm{s}}$ obtained from different fine and coarse AGS with $\mathrm{M}_{\mathrm{s}}$ calculated from neural network $(\mathrm{NN})$ model [8]. 